\title{
The Effects of Etomidate and Propofol Induction on Hemodynamic and Endocrine Response in Patients Undergoing Coronary Artery Bypass Graft Surgery on Cardiopulmonary Bypass
}

\author{
Anil K. Pandey ${ }^{1}$, Neeti Makhija', Sandeep Chauhan ${ }^{1}$, Sambhunath Das ${ }^{1}$, Usha Kiran', \\ Akshya Kumar Bisoi ${ }^{2}$, Ramakrishnan Lakshmy ${ }^{3}$ \\ ${ }^{1}$ Departments of Cardiac Anaesthesia, All India Institute of Medical Sciences, New Delhi, India \\ ${ }^{2}$ Departments of Cardiac Surgery, All India Institute of Medical Sciences, New Delhi, India \\ ${ }^{3}$ Departments of Cardiac Biochemistry, All India Institute of Medical Sciences, New Delhi, India \\ Email: anilpandey18@gmail.com
}

Received April 22, 2012; revised May 26, 2012; accepted June 22, 2012

\begin{abstract}
Aim: To compare the effects of propofol and etomidate induction on hemodynamic parameters and serum cortisol levels in patients with normal left ventricular function undergoing elective coronary artery bypass graft surgery on cardiopulmonary bypass. Material and Method: After approval from the Institute Ethics committee hundred American Society of Anesthesiologists (ASA) grade II or III patients undergoing scheduled coronary artery bypass surgery on cardiopulmonary bypass were enrolled in the study. Patients were allocated randomly to receive either propofol or etomidate for anesthesia induction. Anesthesia was maintained in both groups with sevoflurane, vecuronium bromide for muscle relaxation $(0.1 \mathrm{mg} / \mathrm{kg}$, boluses) and fentanyl up to a total dose of $20 \mathrm{mcg} / \mathrm{kg}$. Result: The baseline serum cortisol values were within normal limits in both the groups. The serum cortisol levels in the propofol group increased more than two fold, whereas the values in the etomidate group decreased by close to fifty percent on weaning from cardiopulmonary bypass (CPB). There was no significant difference in serum cortisol levels in the two groups at twenty-four hours after induction, although the values were close to double the baseline levels. Hemodynamically, etomidate group was more stable than propofol group following induction of anesthesia $(\mathrm{P}<0.05)$. Conclusion: The surge in serum cortisol levels on the initiation of CPB seen after the use of propofol is prevented by the use of etomidate. Serum cortisol levels in both groups are well above the baseline at twenty-four hours without any untoward effects. Etomidate provides more stable hemodynamic parameters when used for induction of anesthesia as compared to propofol.
\end{abstract}

Keywords: Etomidate; Propofol; Coronary Artery Bypass Grafting (CABG); Cardiopulmonary Bypass (CPB)

\section{Introduction}

The considerations for induction of anesthesia in patients with coronary artery disease include hemodynamic stability, amelioration of the stress response to intubation and the continued maintenance of the balance between myocardial oxygen demand and supply [1,2].

Propofol and etomidate are well known anesthetic agents routinely used for the induction of anesthesia for cardiac surgery including coronary artery bypass grafting (CABG) [3]. The two drugs however have different induction characteristics. Etomidate was first introduced in the early seventies, but was soon withdrawn, because of anaphylactic reactions to a stabilizing agent Cremaphore EL. There were also concerns about reductions in the serum cortisol levels and effects thereof caused by con- comitant adrenal suppression by the drug. It has a very stable cardiovascular profile [4-7] and has been recently reintroduced in India as an induction agent. Etomidate is recommended as an induction agent for patients with poor left ventricular (LV) function. Propofol on the other hand may cause a reduction in systemic vascular resistance and subsequent hypotension, which however may be controlled with careful titration of the dose and speed of injection [8].

Etomidate is known to cause a reduction in serum cortisol levels after even a single dose, leading to reduced cortisol levels for up to twenty-four hours [9].

The reduction in serum cortisol levels offered by etomidate may be beneficial provided it does not persist in the post operative period, when the body's circulatory reflexes need to be intact for the maintenance of hemodynamic 
parameters.

This study was conducted to allay the anxiety related to the use of etomidate for anesthetic induction in cardiac patients and compares the effect of anesthetic induction with single dose etomidate versus propofol on serum cortisol levels and hemodynamics.

\section{Hypothesis}

Etomidate used as a single bolus dose for induction of anesthesia does not produce long-term adrenal suppression and has a more favorable hemodynamic profile compared to propofol, in patients undergoing CABG surgery on cardiopulmonary bypass (CPB).

\section{Materials and Methods}

The study was conducted at the Cardiothoracic Centre, All India Institute of Medical Sciences, New Delhi, India after ethical approval from the Institute's ethics committee. Hundred consecutive patients with normal LV function undergoing CABG surgery with use of CPB were enrolled into the trial.

Patients undergoing emergency surgery, having preexisting arrhythmias, congestive cardiac failure, renal dysfunction (serum creatinine $>2 \mathrm{mg} / \mathrm{dl}$ ) pre-existing bleeding and coagulation abnormalities, or on mechanical ventilation or on steroid therapy were excluded from the study.

Fifty patients each were randomly allocated to either the propofol $(\mathrm{P})$ or the etomidate $(\mathrm{E})$ group and the selected agent was used for induction of anesthesia. The randomization was computer aided and carried out at registration level of the cardiac surgery out patient department of the hospital.

As part of the institute protocol, all patients were premedicated with Injection morphine $0.1 \mathrm{mg} / \mathrm{kg}$ and injection phenargan $0.5 \mathrm{mg} / \mathrm{kg}$ intramuscularly half an hour prior to induction of anesthesia.

On entry to the operation theatre, intravenous, intraarterial and pulmonary artery catheters were inserted after local anesthetic infiltration of the insertion site. Patient monitoring was initiated as per institute protocol in the form of hemoglobin saturation percentage of oxygen $\left(\mathrm{SpO}_{2}\right)$, electro-cardiogram (ECG), end tidal carbondioxide $\left(\mathrm{EtCO}_{2}\right)$, invasive blood pressure (IBP), pulmonary capillary wedge pressure and intermittent cardiac output. Anesthesia was induced with either propofol (2 $\mathrm{mg} / \mathrm{kg})$ or etomidate $(0.2 \mathrm{mg} / \mathrm{kg})$ as per group allocation. Endotracheal intubation was performed after achieving muscle relaxation with rocuronium bromide in the dose of $0.1 \mathrm{mg} / \mathrm{kg}$. Mechanical ventilation was instituted to maintain eucapnia. Analgesia was obtained with fentanyl up to a total dose of $20 \mathrm{mcg} / \mathrm{kg}$. Midazolam was administered in divided doses up to a maximum of $0.2 \mathrm{mg} / \mathrm{kg}$. Sevoflurane was administered for maintenance of anes- thesia and dosage titrated to effect.

The baseline hemodynamic parameters in the form of heart rate (HR), blood pressure (BP), central venous pressure (CVP), pulmonary capillary wedge pressure (PCWP), cardiac output (CO) (by repeated bolus thermo-dilution), Cardiac Index (CI), systemic vascular resistance and index (SVR \& SVRI) and pulmonary vascular resistance and index (PVR \& PVRI) were recorded prior to induction and then at five minutes post endotracheal intubation.

Heparin in the dose of $04 \mathrm{mg} / \mathrm{kg}$ was administered prior to initiation of CPB. A hematocrit of at least 30\% was maintained during CPB. Heparin was reversed with protamine in the dose of $4.5 \mathrm{mg} / \mathrm{kg}$ after weaning the patient from CPB.

The serum cortisol values were recorded at 3 time points -1) Baseline before induction of anesthesia; 2) After protamine reversal of heparin after termination of CPB and 3) At twenty-four hours. Patients were observed postoperatively for any adverse effects.

\section{Statistical Analysis}

Data analysis was carried out using STATA 9.0 (College Station, Texas, USA). Data were summarized as number (\%) or mean + SD/median (range) as appropriate. Baseline categorical and continuous variables were compared between the groups using Fisher's exact test and Student's t test respectively. Hemodynamic variables were compared between the groups using Student's t test for independent samples. The primary outcome (serum cortisol) of the study was compared between the groups using Wilcoxon Rank Sum test since the data was nonnormal. The $\mathrm{P}$ value less than 0.05 were considered significant.

\section{Results}

The demographic characteristics, namely, age, height, weight and sex distribution were similar in both the groups (Table 1).

The baseline hemodynamic parameters in the form of heart rate, blood pressure (systolic and diastolic), central venous pressure, pulmonary capillary wedge pressure, car-

Table 1. Demographic profile.

\begin{tabular}{ccc}
\hline & $\begin{array}{c}\text { Etomidate } \\
(\mathrm{n}=50)\end{array}$ & $\begin{array}{c}\text { Propofol } \\
(\mathrm{n}=50)\end{array}$ \\
\hline Age (years) & $57.26 \pm 8.87$ & $57.33 \pm 9.48$ \\
Sex (M/F) & $49 / 1$ & $49 / 1$ \\
Weight (kg) & $67.66 \pm 9.13$ & $67.53 \pm 11.4$ \\
\hline
\end{tabular}

Values are mean \pm standard deviation. 
diac output, cardiac index, systemic vascular resistance, systemic vascular resistance index, pulmonary vascular resistance and pulmonary resistance index were similar in both the groups (Table 2).

The hemodynamic parameter values at five minutes post endotracheal intubation after anesthetic induction were compared between the two groups (Table 3). The systolic blood pressure, the diastolic blood pressure, the systemic vascular resistance and the systemic vascular resistance index were significantly different between the two groups at five minutes post induction and were statistically significantly lower in the propofol group.

Table 2. Baseline hemodynamic data.

\begin{tabular}{|c|c|c|c|}
\hline $\begin{array}{l}\text { Hemodynamic } \\
\text { Parameters at } 05 \text { min } \\
\text { post induction }\end{array}$ & Etomidate $(\mathrm{n}=50)$ & Propofol $(n=50)$ & P value* \\
\hline $\begin{array}{l}\text { Heart rate } \\
\text { (per min) }\end{array}$ & $68.8 \pm 18.26$ & $69.13 \pm 11.96$ & 0.95 \\
\hline $\begin{array}{c}\text { Systolic blood } \\
\text { pressure (mmHg) }\end{array}$ & $138.2 \pm 19.88$ & $150.2 \pm 31.32$ & 0.22 \\
\hline $\begin{array}{c}\text { Diastolic blood } \\
\text { pressure (mmHg) }\end{array}$ & $76.8 \pm 8.81$ & $79.06 \pm 16.33$ & 0.64 \\
\hline $\begin{array}{c}\text { Central venous } \\
\text { pressure (mmHg) }\end{array}$ & $6.13 \pm 3.22$ & $7.6 \pm 4.08$ & 0.26 \\
\hline $\begin{array}{c}\text { Pulmonary capillary } \\
\text { wedge pressure } \\
\text { (mmHg) }\end{array}$ & $6.66 \pm 3.43$ & $9.53 \pm 2.99$ & 0.02 \\
\hline $\begin{array}{l}\text { Cardiac output } \\
\text { (L/min) }\end{array}$ & $4.31 \pm 1.22$ & $4.01 \pm 1.46$ & 0.54 \\
\hline $\begin{array}{l}\text { Cardiac index } \\
\left(\mathrm{L} / \mathrm{min} / \mathrm{m}^{2}\right)\end{array}$ & $2.43 \pm 0.58$ & $2.30 \pm 0.77$ & 0.62 \\
\hline $\begin{array}{l}\text { Systemic vascular } \\
\text { resistance } \\
\left(\text { dynes } / \mathrm{cm}^{5}\right)\end{array}$ & $1762.33 \pm 442.85$ & $2054.67 \pm 866.59$ & 0.25 \\
\hline $\begin{array}{l}\text { Systemic vascular } \\
\text { resistance index } \\
\left(\text { dynes } / \mathrm{cm}^{5} / \mathrm{m}^{2}\right)\end{array}$ & $3060.4 \pm 604.93$ & $3540.53 \pm 1458.68$ & 0.25 \\
\hline $\begin{array}{l}\text { Pulmonary vascular } \\
\text { resistance } \\
\left(\text { dynes } / \mathrm{cm}^{5}\right)\end{array}$ & $166.53 \pm 96.1$ & $141 \pm 80.71$ & 0.44 \\
\hline $\begin{array}{l}\text { Pulmonary vascular } \\
\text { resistance index } \\
\left(\text { dynes } / \mathrm{cm}^{5} / \mathrm{m}^{2}\right)\end{array}$ & $294.93 \pm 176.44$ & $243.26 \pm 134.95$ & 0.39 \\
\hline
\end{tabular}

Values are mean $\pm \mathrm{SD}, * \mathrm{P}$ value $<0.05$ is considered significant.
Table 3. Hemodynamic data at five minutes post induction.

Hemodynamic

Parameters at 05 min Etomidate $(n=50)$ Propofol $(n=50) \quad$ P value* post induction

\begin{tabular}{|c|c|c|c|}
\hline $\begin{array}{l}\text { Heart rate } \\
\text { (per min) }\end{array}$ & $73.66 \pm 16.36$ & $75.46 \pm 17.09$ & 0.77 \\
\hline $\begin{array}{c}\text { Systolic blood } \\
\text { pressure (mmHg) }\end{array}$ & $120.2 \pm 17.11$ & $99.66 \pm 10.86$ & $0.0005^{*}$ \\
\hline $\begin{array}{c}\text { Diastolic blood } \\
\text { pressure (mmHg) }\end{array}$ & $72.66 \pm 10.34$ & $59.8 \pm 8.92$ & $0.0011^{*}$ \\
\hline $\begin{array}{c}\text { Central venous } \\
\text { pressure (mmHg) }\end{array}$ & $7.6 \pm 2.84$ & $7.33 \pm 2.94$ & 0.866 \\
\hline $\begin{array}{l}\text { Pulmonary capillary } \\
\text { wedge pressure } \\
\text { (mmHg) }\end{array}$ & $8.46 \pm 3.48$ & $9.4 \pm 4.71$ & 0.5426 \\
\hline $\begin{array}{l}\text { Cardiac output } \\
\text { (L/min) }\end{array}$ & $3.71 \pm 1.11$ & $3.91 \pm 1.27$ & 0.649 \\
\hline $\begin{array}{l}\text { Cardiac index } \\
\left(\mathrm{L} / \mathrm{min} / \mathrm{m}^{2}\right)\end{array}$ & $2.09 \pm 0.54$ & $2.25 \pm 0.64$ & 0.465 \\
\hline $\begin{array}{l}\text { Systemic vascular } \\
\text { resistance } \\
\left(\text { dynes } / \mathrm{cm}^{5}\right)\end{array}$ & $1853 \pm 593.89$ & $1448.06 \pm 468.43$ & $0.0474^{*}$ \\
\hline $\begin{array}{l}\text { Systemic vascular } \\
\text { resistance index } \\
\left(\text { dynes } / \mathrm{cm}^{5} / \mathrm{m}^{2}\right)\end{array}$ & $3224.93 \pm 940.53$ & $2488.73 \pm 773.86$ & $0.026^{*}$ \\
\hline $\begin{array}{l}\text { Pulmonary vascular } \\
\text { resistance } \\
\left(\text { dynes } / \mathrm{cm}^{5}\right)\end{array}$ & $141.33 \pm 72.77$ & $141.26 \pm 60.35$ & 0.997 \\
\hline $\begin{array}{l}\text { Pulmonary vascular } \\
\text { resistance index } \\
\left(\text { dynes } / \mathrm{cm}^{5} / \mathrm{m}^{2}\right)\end{array}$ & $240.26 \pm 101.28$ & $243.93 \pm 106.04$ & 0.95 \\
\hline
\end{tabular}

There was no difference in the baseline serum cortisol levels between the two groups. The serum cortisol levels at the time of weaning off $\mathrm{CPB}$ in the etomidate group were significantly lower but still within normal levels (9 - $25 \mathrm{mcg} / \mathrm{dl}$ ) as compared to the propofol group (Table 4). The average cortisol value was reduced by almost $50 \%$ in the etomidate group, whereas it increased by more than two and a half fold in the propofol group at the time of weaning from CPB compared to baseline cortisol values (Table 4).

The serum cortisol level at 24 hours was higher as compared to baseline values in both the groups. In the etomidate group the serum cortisol returned to normal levels 
Table 4. Comparison of serum cortisol values between baseline and coming off $\mathrm{CPB}$.

\begin{tabular}{cccc}
\hline & \multicolumn{3}{c}{ Serum Cortisol mcg/dL (Mean \pm SD) } \\
Group & Baseline & After coming off CPB & P value \\
\hline Etomidate $(\mathrm{n}=50)$ & $14.92 \pm 8.39$ & $8.14 \pm 3.00$ & 0.0015 \\
Propofol $(\mathrm{n}=50)$ & $11.4 \pm 8.32$ & $28.82 \pm 14.52$ & 0.0054 \\
& & & \\
\hline P value & 0.115 & 0.000 & \\
\hline
\end{tabular}

Values are mean $\pm \mathrm{SD}$, P value $<0.05$ is considered significant.

which was however almost twice the baseline value. In the propofol group the serum cortisol levels remained high and were almost three times the base line values (Table 5).

None of the patients had any adverse effects that could be attributed to cortisol suppression.

\section{Discussion}

Etomidate and propofol are well known for their anesthesia induction properties.

Etomidate (Lipuro. B Braun. Melsungen. Germany) is a short acting intravenous anesthetic agent used for the induction of general anesthesia [10]. It was introduced as an intravenous agent in 1972 in Europe and in 1983 in United States [11]. It has a rapid onset of action and a safe cardiovascular risk profile, and therefore is less likely to cause a significant drop in blood pressure than other induction agents [12-14]. It is an ideal induction agent for patients who are haemodynamically unstable [15].

The normal adult serum cortisol levels are $05 \mathrm{mcg} / \mathrm{dl}$ to $25 \mathrm{mcg} / \mathrm{dl}$.

Etomidate suppresses corticosteroid synthesis in the adrenal cortex by reversibly inhibiting 11-beta-hydroxylase, an enzyme important in adrenal steroid production leading to primary adrenal suppression [16]. Using a continuous infusion may be detrimental and may lead to increased mortality [17]. The cortisol suppression induced by a single dose of etomidate is almost always limited to 24 hours [9], and therefore does not pose any threat of prolonged adrenocortical suppression. The cortisol levels in this study also returned to normal levels at twenty-four hours post induction with etomidate.

Propofol (Diprivan. AstraZeneca. Cheshire. United Kingdom) is a short-acting, intravenously administered hypnotic agent.

Propofol has been proposed to have several mechanisms of action [18-20], both through potentiation of GABA receptor activity, thereby slowing the channelclosing time [21-23], and also acting as a sodium channel
Table 5. Comparison of serum cortisol values between baseline and 24 hours.

\begin{tabular}{cccc}
\hline \multirow{2}{*}{ Group } & \multicolumn{3}{c}{ Serum Cortisol mcg/dL (Mean \pm SD) } \\
\cline { 2 - 4 } & Baseline & 24 hours post surgery & P value \\
\hline Etomidate $(\mathrm{n}=50)$ & $14.92 \pm 8.39$ & $28.67 \pm 10.94$ & 0.001 \\
Propofol (n = 50) & $11.4 \pm 8.32$ & $32.62 \pm 14.58$ & 0.001 \\
P value & 0.115 & 0.518 & \\
\hline
\end{tabular}

Values are mean \pm SD, $\mathrm{P}$ value $<0.05$ is considered significant.

blocker [24,25]. Recent research has also suggested that the endocannabinoid system may contribute significantly to propofol's anesthetic action and to its unique properties [26].

Propofol causes vasodilatation and may result in transient fall in systemic blood pressure. The pain on propofol injection can be mitigated by pretreatment with lidocaine [27].

Cortisol like other steroid hormones exerts its effects by first interacting with the intracellular receptors in the target cells. Being lipid soluble it easily diffuses through the cell membrane. Once inside the cell, it binds with its protein receptor in the cytoplasm. The hormone receptor complex then interacts with specific regulatory DNA sequences called glucocorticoid response elements to induce or repress gene transcription.

Baseline cortisol levels in the human body peak between 0700 and $0800 \mathrm{hrs}$ and range from 9 to $25 \mathrm{mcg} / \mathrm{dl}$, the levels decline by 1600 hrs and range between 3 to 12 $\mathrm{mcg} / \mathrm{dl}$.

Cortisol is a catabolic hormone and mobilises carbohydrates, proteins and fat to ultimately cause a marked rise in the blood glucose levels, which is resistant to control by insulin.

Increased cortisol also causes a reduction in the inflammatory response, by stabilizing lysosomal membranes, decreasing capillary permeability, reduced migration of white blood cells to the inflamed area and phagocytosis of damaged cells. It suppresses the immune system causing a marked reduction in lymphocyte production. There is a reduction in interleukin release from the white blood cells. There is also a reduction in established inflammation on exogenous administration. Inflammatory response to allergic reactions is also blocked.

Cortisol being the precursor for catecholamine synthesis in the body, it is postulated that reduction in levels would have a negative impact on the mounting of the stress response to CPB by the body.

Cardiopulmonary bypass is known to produce a stress 
response by means of stimulation of the sympathetic adrenal system. Plasma levels of sympathomimetic amines such as epinephrine and nor-epinephrine may increase several thousand folds in response to CPB [28]. This may lead to systemic inflammatory response, a catabolic state and may delay patient recovery after CPB. The suppression of the adrenal stress response in the form of cortisol suppression by etomidate may be beneficial, as seen in our study where the serum cortisol levels on weaning our patients from CPB were significantly lower but still within normal levels in the etomidate group as compared to the propofol group. These levels of serum cortisol were suppressed for the first twenty-four hours, when the stress response of the patient could have been maximal in the form of response to pain (sternotomy, surgical dissection around aorta, chest tube insertions), extubation and physiotherapy. The levels of serum cortisol however returned to almost normal levels by twenty-four hours. The patients who received propofol too, did not manifest any complications of the much higher serum cortisol levels, as probably, this was a subset of patients with good cardiopulmonary reserve, and as such were not liable to have any complications from a heightened stress response.

We know that a severe stress response to CPB may be detrimental for patient survival in the setting of disturbed myocardial oxygen balance, frequently seen in coronary artery disease patients, especially in the immediate postoperative period. Hence the maintenance of serum cortisol levels within normal limits on exposure to CPB may be beneficial in these patients. It is reiterated that the increase in serum cortisol in response to stress is the body's normal reaction. This has to be weighed against the benefit extended by maintenance of near normal hemodynamics by reduced serum cortisol levels. The elevation in serum cortisol is stress induced and not vice versa.

In this study the serum cortisol values in the etomidate group were much lower than in the propofol group at the time of protamine reversal of heparin after weaning off $\mathrm{CPB}$ presumably due to the suppression of cortisol synthesis by etomidate.

It was also noted that the SBP, DBP, SVR and SVRI were significantly lower at five minutes post induction (Table 2) in the propofol group compared to the etomidate group, indicating that etomidate is associated with more stable hemodynamics on induction of anesthesia, presumably due to prevention of the cortisol surge on induction by temporary suppression of the cortisol synthesis. This is unlike propofol where careful titration of dosage and vigilance is mandatory for countering the sudden reduction in SVR for maintenance of stable hemodynamics.

Maintenance of near normal stress hormones levels under anesthesia is associated with better outcomes [28]. The maintenance of serum cortisol in the normal range and stable hemodynamics may be advantageous in the subset of patients in this study. Etomidate may be a superior anesthetic induction agent compared to propofol in the patient subgroup undergoing $C A B G$ with use of $C P B$.

\section{Limitations of the Study}

The study was conducted on a small group of patients with normal LV function by the same surgical team. A large multi-centric trial, on varied patient categories, undergoing different surgical therapies may be needed to further validate the obtained results.

\section{Conclusions}

There is a surge in serum cortisol levels on the initiation of CPB seen after the use of propofol. This is not present in the etomidate group, where instead the serum cortisol level reduced to fifty percent. Serum cortisol levels returned to near normal range at twenty-four hours without any untoward effects. The values though were almost twice the baseline.

Etomidate provides more stable hemodynamic parameters when used for induction of anesthesia as compared to propofol.

Etomidate can therefore be safely used as an anaesthetic induction agent in patients with good LV function for CABG on CPB without serious cortisol suppression lasting more than twenty-four hours.

\section{REFERENCES}

[1] R. G. Merin, "Is Anesthesia Beneficial to the Ischemic Heart?” Anesthesiology, Vol. 53, No. 6, 1980, pp. 439-440. doi:10.1097/00000542-198012000-00001

[2] E. A. Moffit and D. H. Sethna, "The Coronary Circulation and Myocardial Oxygenation in Coronary Artery Disease: Effects of Anesthesia,” Anesthesia \& Analgesia, Vol. 65, No. 4, 1986, pp. 395-410. doi:10.1213/00000539-198604000-00018

[3] R. Singh, M. Choudhury, P. M. Kapoor and U. Kiran, “A Randomized Trial of Anesthetic Induction Agents in Patients with Coronary Artery Disease and Left Ventricular Dysfunction,” Annals of Cardiac Anaesthesia, Vol. 13, No. 3, 2010, pp. 217-223. doi:10.4103/0971-9784.69057

[4] A. Criado, J. Maseda, E. Navarro, A. Escarpa and F. Avello, "Induction of Anesthesia with Etomidate: Haemodynamic Study of 36 Patients,” British Journal of Anaesthesia, Vol. 52, No. 8, 1980, pp. 803-806. doi:10.1093/bja/52.8.803

[5] T. J. Ebert, M. Muzi, R. Berens, D. Goff and J. P. Kampine, "Sympathetic Responses to Induction of Anesthesia in Humans with Propofol or Etomidate," Anesthesiology, Vol. 76, No. 5, 1992, pp. 725-733. doi:10.1097/00000542-199205000-00010

[6] D. F. Stowe, Z. J. Bosnjak and J. P. Kampine, "Comparison of Etomidate, Ketamine, Midazolam, Propofol, and Thiopental on Function and Metabolism of Isolated Hearts," 
Anesthesia \& Analgesia, Vol. 74, No. 4, 1992, pp. 547558. doi:10.1213/00000539-199204000-00015

[7] B. Riou, Y. Lecarpentier and P. Viars, "Effects of Etomidate on the Cardiac Papillary Muscle of Normal Hamsters and Those with Cardiomyopathy," Anesthesiology, Vol. 78, No. 1, 1993, pp. 83-90. doi:10.1097/00000542-199301000-00013

[8] T. Hosten, M. Solak, L. Kilicken, D. Ozdamar and K. Toker, "The Effects of Etomidate and Propofol Induction on Hemodynamic and Endocrine Response Undergoing CABG Surgery,” Trakya Universitesi Tip Fakultesi Dergisi, Vol. 24, No. 2, 2007, pp. 114-126.

[9] A. M. Zurick, H. Sigurdsson, L. S. Koehler, et al., "Magnitude and Time Course of Perioperative Adrenal Suppression with Single Dose Etomidate in Male Adult Cardiac Surgical Patients,” Anesthesiology, Vol. 65, No. 3A, 1986, p. A248.

[10] D. R. Vinson and D. R. Bradbury, "Etomidate for Procedural Sedation in Emergency Medicine,” Annals of Emergency Medicine, Vol. 39, No. 6, 2002, pp. 592-598. doi:10.1067/mem.2002.123695

[11] J. M. Bergen and D. C. Smith, "A Review of Etomidate for Rapid Sequence Intubation in the Emergency Department,” The Journal of Emergency Medicine, Vol. 15, No. 2, 1998, pp. 221-230. doi:10.1016/S0736-4679(96)00350-2

[12] P. J. Zed, R. B. Abu-Laban and D. W. Harrison, "Intubating Conditions and Hemodynamic Effects of Etomidate for Rapid Sequence Intubation in the Emergency Department: An Observational Cohort Study,” Academic Emergency Medicine, Vol. 13, No. 4, 2006, pp. 378-383. doi:10.1111/j.1553-2712.2006.tb00313.x

[13] P. E. Sokolove, D. D. Price and P. Okada, "The Safety of Etomidate for Emergency Rapid Sequence Intubation of Pediatric Patients,” Pediatric Emergency Care, Vol. 16, No. 1, 2000, pp. 18-21. doi:10.1097/00006565-200002000-00005

[14] C. M. Hohl, C. H. Kelly-Smith, T. C. Yeung, D. D. Sweet, M. M. Doyle-Waters and M. Schulzer, "The Effect of a Bolus Dose of Etomidate on Cortisol Levels, Mortality, and Health Services Utilization: A Systematic Review," Annals of Emergency Medicine, Vol. 56, No. 2, 2010, pp. 105-113. doi:10.1016/j.annemergmed.2010.01.030

[15] M. L. Sivilotti, M. R. Filbin, H. E. Murray, P. Slasor and R. M. Walls, "Does the Sedative Agent Facilitate Emergency Rapid Sequence Intubation?” Academic Emergency Medicine, Vol. 10, No. 6, 2003, pp. 612-620. doi:10.1197/aemj.10.6.612

[16] R. L. Wagner, P. F. White, P. B. Kan, M. H. Rosenthal and D. Feldman, "Inhibition of Adrenal Steroidogenesis by the Anesthetic Etomidate,” The New England Journal of Medicine, Vol. 310, No. 22, 1984, pp. 1415-1421. doi:10.1056/NEJM198405313102202

[17] I. M. Ledingham and I. Watt, "Influence of Sedation in Critically Ill Multiple Trauma Patients,” The Lancet, Vol.
321, No. 8336, 1983, p. 1270. doi:10.1016/S0140-6736(83)92712-5

[18] G. Trapani, C. Altomare, G. Liso, E. Sanna and G. Biggio, "Propofol in Anesthesia. Mechanism of Action, Structure-Activity Relationships, and Drug Delivery,” Current Medicinal Chemistry, Vol. 7, No. 2, 2000, pp. 249-271.

[19] Y. Kotani, M. Shimazawa, S. Yoshimura, T. Iwama and H. Hara, "The Experimental and Clinical Pharmacology of Propofol, an Anesthetic Agent with Neuroprotective Properties," CNS Neuroscience and Therapeutics, Vol. 14, No. 2, 2008, pp. 95-106.

[20] C. Vanlersberghe and F. Camu, "Propofol," Handbook of Experimental Pharmacology, Vol. 182, 2008, pp. 227-252.

[21] G. Trapani, A. Latrofa, M. Franco, C. Altomare, E. Sanna, M. Usala, G. Biggio and G. Liso, "Propofol Analogues. Synthesis, Relationships between Structure and Affinity at GABAA Receptor in Rat Brain, and Differential Electrophysiological Profile at Recombinant Human GABAA Receptors,” Journal of Medicinal Chemistry, Vol. 41, No. 11, 1998, pp. 1846-1854. doi:10.1021/jm970681h

[22] M. D. Krasowski, A. Jenkins, P. Flood, A. Y. Kung, A. J. Hopfinger and N. L. Harrison, "General Anesthetic Potencies of a Series of Propofol Analogs Correlate with Potency for Potentiation of Gamma-Aminobutyric Acid (GABA) Current at the GABA (A) Receptor But Not with Lipid Solubility," Journal of Pharmacology and Experimental Therapeutics, Vol. 297, No. 1, 2001, pp. 338-351.

[23] M. D. Krasowski, X. Hong, A. J. Hopfinger and N. L. Harrison, "4D-QSAR Analysis of a Set of Propofol Analogues: Mapping Binding Sites for an Anesthetic Phenol on the GABAA Receptor,” Journal of Medicinal Chemistry, Vol. 45, No. 15, 2002, pp. 3210-3221. doi:10.1021/jm010461a

[24] G. Haeseler and M. Leuwer, "High-Affinity Block of Voltage-Operated Rat IIA Neuronal Sodium Channels by 2,6-Di-tert-butylphenol, a Propofol Analogue,” European Journal of Anaesthesiology, Vol. 20, No. 3, 2003, pp. 220-224. doi:10.1097/00003643-200303000-00007

[25] G. Haeseler, M. Karst, N. Foadi, S. Gudehus, A. Roeder, H. Hecker, R. Dengler and M. Leuwer, "High-Affinity Blockade of Voltage-Operated Skeletal Muscle and Neuronal Sodium Channels by Halogenated Propofol Analogues,” British Journal of Pharmacology, Vol. 155, No. 2, 2008, pp. 265-275. doi:10.1038/bjp.2008.255

[26] C. J. Fowler, "Possible Involvement of the Endocannabinoid System in the Actions of Three Clinically Used Drugs,” Trends in Pharmacological Sciences, Vol. 25, No. 2, 2004, pp. 59-61. doi:10.1016/j.tips.2003.12.001

[27] Drugs.com, "Propofol Drug Information, Professional," 2011. http://www.drugs.com/mmx/propofol.html

[28] K. J. S. Anand and P. R. Hickey, "Halothane-Morphine Compared with High Dose Sufentanil for Anesthesia and Postoperative Analgesia in Neonatal Cardiac Surgery," The New England Journal of Medicine, Vol. 326, No. 1, 1992, pp. 1-9. doi:10.1056/NEJM199201023260101 